\title{
OCCURRENCE OF POST-INJECTION DELIRIUM/SEDATION SYNDROME AFTER APPLICATION OF OLANZAPINE LONG-ACTING INJECTION DURING ONE YEAR PERIOD
}

\author{
Suzana Uzun ${ }^{1,2}$, Oliver Kozumplik ${ }^{1,2}$, Ivan Ćelić ${ }^{1}$, Nela Pivac ${ }^{3}$ \& Ninoslav Mimica ${ }^{1,4}$ \\ ${ }^{1}$ University Psychiatric Hospital Vrapče, Zagreb, Croatia \\ ${ }^{2}$ University Josip Juraj Strossmayer Osijek, School of Medicine, Osijek, Croatia \\ ${ }^{3}$ Ruđer Bošković Institute, Division of Molecular Medicine, \\ Laboratory for Molecular Neuropsychiatry, Zagreb, Croatia \\ ${ }^{4}$ School of Medicine, University of Zagreb, 10000 Zagreb, Croatia
}

received: 15.3.2017;

revised: 27.7.2017;

accepted: 1.9.2017

\begin{abstract}
SUMMARY
Introduction: The aim was to report the occurrence of after application of olanzapine long-acting injection (OLAI) in patients with schizophrenia during one year period.

Subjects and methods: During one year period, OLAI was applied to 30 patients with schizophrenia (18 men, 12 women) who were non-adherent to previous treatment with oral olanzapine. Patients were 20-58 years of age (39 years old on average),

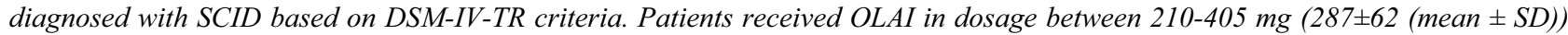
every 2-4 weeks.

Results: Out of 30 patients that received OLAI, 29 patients improved significantly without side-effects, and one patient developed post-injection delirium/sedation syndrome (PDSS). The patient's somatic condition stabilized and treatment with OLAI was discontinued due to the PDSS.
\end{abstract}

Conclusion: The occurrence of PDSS is not common and when it occurs, in our experience, it was reversible.

Key words: olanzapine - patients - post-injection delirium/sedation syndrome - schizophrenia - treatment

\section{INTRODUCTION}

Schizophrenia is a chronic, severe and recurrent brain disorder that requires continuous, long-term treatment with antipsychotic medication to improve the clinical state, to minimize relapses and provide clinical benefits to patients (De Berardis et al. 2013). Medication non-adherence in schizophrenia is often associated with negative consequences, including symptom exacerbation, frequent emergency room visits, re-hospitalizations and relapses (Lindemayer 2010). An advance in the treatment of schizophrenia is the development of long-acting intramuscular formulations of antipsychotics, such as olanzapine long-acting injection (Detke et al. 2010). Long-acting injectable formulations of secondgeneration antipsychotics provide constant medication delivery and offer the potential for improved adherence (De Berardis et al. 2013). Olanzapine long-acting injection is a salt-based depot antipsychotic combining olanzapine and pamoic acid (McDonnell et al. 2010). Olanzapine long-acting injection (OLAI), or olanzapine pamoate, is a second generation antipsychotic longacting formulation. The most relevant adverse event of OLAI is the post-injection delirium/sedation syndrome (PDSS), occurring at a rate of $0.07 \%$ of injections or in $1.4 \%$ of patients (Naber 2011). While non-adherence is a major problem in the treatment of schizophrenia, olanzapine pamoate can improve adherence, though its use is limited by its safety profile (Schöttle et al. 2013). The program for patients who need to stay during period of observation after application of OLAI was designed on the Department for biological psychiatry and psychogeriatrics. The patients have accepted that program and during period of observation they are educated about different psychiatric disorders, treatment options, and also the aim is to improve patients' social and communicational skills. This way, activities during period of observation have benefits for treatment of patients.

The aim of this paper was to report the occurrence of post-injection delirium/sedation syndrome after application of OLAI in patients with schizophrenia during the one year period.

\section{SUBJECTS AND METHODS}

During a period of one year, in the University Psychiatric Hospital Vrapče, Department for biological psychiatry and psychogeriatrics, OLAI was applied to 30 patients with schizophrenia (18 men, 12 women) who were non-adherent to previous treatment with oral olanzapine. Before initiation of treatment with OLAI, all patients received oral olanzapine. Patients were 2058 years of age (39 years old on average), diagnosed with SCID based on DSM-IV-TR criteria. Patients

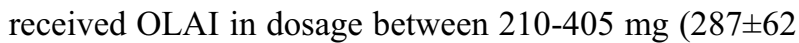
$($ mean $\pm \mathrm{SD})$ ) every 2-4 weeks. 


\section{RESULTS}

The most common applied OLAI dosage was 300 $\mathrm{mg}(52.89 \%$ of injections). Out of 30 patients that received OLAI, 29 patients improved significantly without side-effects, and one patient developed postinjection delirium/sedation syndrome (PDSS).

PDSS developed in a female patient with schizophrenia, 32 years old, who was in a psychiatric treatment for the past six years, during which she was treated with different antipsychotics. She discontinued antipsychotic treatment at her own will, when she was feeling better. Patient's mental condition was improved during treatment with olanzapine tablets in daily dosage of $10 \mathrm{mg}$. All routine blood analyses and electrocardiogram (ECG) data were within normal, i.e. referent ranges. Because of the non-compliance in anamnesis, application of OLAI was initiated. Four hours after the application of recommended OLAI dose of $210 \mathrm{mg}$ (Lauriello et al. 2008), patient developed PDSS: she became confused and felt asleep soon after; during the sleep that lasted 8 hours she reacted only to a rough stimulation. Patient received $1500 \mathrm{ml}$ of $5 \%$ glucose infusion; specialist of internal medicine was consulted and requested further examination. The values of laboratory parameters, ECG, and computerized tomography (CT) of brain data were normal, within referent ranges. During the next three days, psychomotor retardation gradually vanished. On the fifth day after the application of OLAI, pretibial oedema occurred. The treatment with furosemide $40 \mathrm{mg}$ daily was applied during the next three days, as recommended by the consulted specialist of internal medicine, and this treatment was successful since the pretibial oedema vanished. Repeated examination of all laboratory parameters, ECG and abdominal ultrasound data revealed findings within referent ranges. Ten days after OLAI application, patient's somatic condition stabilized. After close medical supervision and monitoring, treatment with OLAI was discontinued due to PDSS.

\section{DISCUSSION}

In our study PDSS occurred in one out of $30 \mathrm{pa}-$ tients. The occurrence of PDSS was also observed in some previous studies (Detke et al. 2014, McDonnell et al. 2014). In a 6-year, single-arm, open-label extension study with the objective to assess the long-term safety and efficacy of olanzapine long-acting injection (LAI) that was conducted at 127 sites in 25 countries, and included 931 patients with schizophrenia or schizoaffective disorder (18-76 years of age), there were 36 occurrences $(3.9 \%)$ of PDSS, all resolving within 72 hours (McDonnell et al. 2014). In line with this finding, in our study PDSS occurred in 1 (3.3\%) patient. Olanzapine LAI appeared effective as a long-term maintenance treatment, with a safety profile generally consistent with the known profile of oral olanzapine, except for injection-related events (including PDSS) (McDonnell et al. 2014). In the study that compared long-term treatment effectiveness of monthly olanzapine long-acting injection (LAI) with that of oral olanzapine, that included outpatients with 2 or more episodes of psychotic worsening in the past 24 months with Positive and Negative Syndrome Scale total scores lower than 70 , who were randomized to $405 \mathrm{mg} / 4$ weeks of olanzapine LAI $(n=264)$ or $10 \mathrm{mg} / \mathrm{d}$ of oral olanzapine $(n=260)$ for 2 years of open-label treatment, there were no clinically significant group differences in adverse events or safety measures. In these patients, no PDSS events were recorded (Detke et al. 2014).

\section{CONCLUSION}

Our finding supports the need for a 4-hour postinjection observation and further monitoring of the adverse reaction to OLAI in persons with schizophrenia. The occurrence of PDSS is not common and when it occurs, in our experience, was reversible.

\section{Acknowledgements: None.}

\section{Conflict of interest: None to declare.}

\section{Contribution of individual authors:}

Suzana Uzun: design of the study and manuscript, collection and interpretation of data, writing, literature search.

Oliver Kozumplik: interpretation of data, manuscript design, writing, literature search.

Ninoslav Mimica: design of the study, literature search and analyses, editing.

Nela Pivac: participated in the design of the study, statistical analyses as well as interpretation of data

Ivan Ćelić: statistical data processing, literature search.

\section{References}

1. De Berardis D, Marini S, Carano A, Lang AP, Cavuto M, Piersanti $M$ et al.: Efficacy and safety of long acting injectable atypical antipsychotics: a review. Curr Clin Pharmacol 2013; 8:256-64.

2. Detke HC, McDonnell DP, Brunner E, Zhao F, Sorsaburu S, Stefaniak VJ et al.: Post-injection delirium/sedation syndrome in patients with schizophrenia treated with olanzapine long-acting injection, I: analysis of cases. BMC Psychiatry 2010; 10:43.

3. Detke HC, Weiden PJ, Llorca PM, Choukour M, Watson $S B$, Brunner $E$ et al.: Comparison of olanzapine longacting injection and oral olanzapine: a 2-year, randomized, open-label study in outpatients with schizophrenia. J Clin Psychopharmacol 2014; 34:426-34.

4. Lauriello J, Lambert T, Andersen S, Lin D, Taylor CC, McDonnell D: An 8-week, double-blind, randomized, placebo-controlled study of olanzapine long-acting injec- 
tion in acutely ill patients with schizophrenia. J Clin Psychiatry 2008; 69:790-9.

5. Lindenmayer JP: Long-acting injectable antipsychotics: focus on olanzapine pamoate. Neuropsychiatr Dis Treat 2010; 6:261-7.

6. McDonnell DP, Detke HC, Bergstrom RF, Kothare P, Johnson J, Stickelmeyer M et al.: Post-injection delirium/ sedation syndrome in patients with schizophrenia treated with olanzapine long-acting injection, II: investigations of mechanism. BMC Psychiatry 2010; 10:45.
7. McDonnell DP, Landry J, Detke HC: Long-term safety and efficacy of olanzapine long-acting injection in patients with schizophrenia or schizoaffective disorder: a 6-year, multinational, single-arm, open-label study. Int Clin Psychopharmacol 2014; 29:322-31.

8. Naber D: Olanzapine pamoate for the treatment of schizophrenia. Expert Opin Pharmacother 2011; 12:627-33.

9. Schöttle D, Kuhnigk $O \&$ Naber D: Drug safety evaluation of olanzapine pamoate. Expert Opin Drug Saf 2013; 12:897-903.

\section{Correspondence:}

Ass. professor Suzana Uzun, MD, PhD

University Psychiatric Hospital Vrapče Bolnička cesta 32, HR-10090 Zagreb, Croatia

E-mail:suzana.uzun@bolnica-vrapce.hr 